\title{
Relationship between Space-Based Vegetation Productivity Index and Radial Growth of Main Tree Species in the Dry Afromontane Forest Remnants of Northern Ethiopia
}

\author{
1,2,*SIYUM, ZG; ${ }^{3}$ AYOADE, JO; ${ }^{4}$ ONILUDE, MA; ${ }^{2}$ FEYISSA, MT \\ ${ }^{I}$ Pan African University, Life and Earth Sciences (including Health and Agriculture) Institute, University of Ibadan, Ibadan, Nigeria \\ ${ }^{2}$ Hawassa University, Wondo Genet College of Forestry and Natural Resource, P.O. Box 128, Shashemene, Ethiopia \\ ${ }^{3}$ Department of Geography, University of Ibadan, Ibadan, Nigeria \\ ${ }^{4}$ Department of Agricultural and Environmental Engineering, University of Ibadan, Ibadan, Nigeria \\ "Corresponding author Email: zenebegirmay@ gmail.com
}

\begin{abstract}
Investigating the relations between Normalized Difference Vegetation Index (NDVI) and tree growth is vital for quantifying ecosystem primary productivity over large spatial and long temporal scales. In this study, the relationships between forest growth (tree-ring width indices) and space-based measurement of vegetation activity (NDVI) were examined in the dry Afromontane forest remnants of northern Ethiopia. The results showed that radial growth of the main tree species (Juniperus procera, Olea europaea and Podocarpus falcatus) is positively correlated with inter-annual NDVI values. Moreover, the relationships between ring width - rainfall and rainfall - NDVI were positive and significant $(\mathrm{p}<0.05)$, suggesting that rainfall seasonality is an overriding growth-limiting factor in the study region. Rainfall during the wet-season largely controls cambial activities and phenological processes of the founding tree species, and hence affects overall vegetation dynamics in the region. Overall, the study showed the coupling of tree-ring growth and NDVI values with potential implications for understanding forest growth dynamics. Thus, it gives insights to the applicability of NDVI - treerings integration approach to predict landscape-level patterns of vegetation productivity.
\end{abstract}

\section{DOI: https://dx.doi.org/10.4314/jasem.v22i11.12}

Copyright: Copyright $\odot 2018$ Siyum et al. This is an open access article distributed under the Creative Commons Attribution License (CCL), which permits unrestricted use, distribution, and reproduction in any medium, provided the original work is properly cited.

Dates: Received: 01 November 2018; Revised: 26 November 2018; Accepted 28 November 2018

Keywords: Dry Afromontane Forest, Remote-sensing, Tree-rings

Climate-induced challenge is a growing concern in the dry tropics and it is threatening the counterbalancing potential of these ecosystems (IPCC, 2013). Tropical dry forests play a major role in balancing the global carbon cycle (Miles et al., 2006). Therefore, understanding their response to climate change is of high priority for predicting future dynamics and for informing adaptation and mitigation policies (Corlett, 2011). This needs information on long-term response of vegetation to climate change. Since long-term and instrument-acquired climate records in the dry tropics are spatially and temporally limited, the use of proxy data is crucial for modeling current climate/vegetation dynamics and future vegetation shifts (Gebrekirstos et al., 2011). One of the most suitable proxies used to measure annual variability in radial growth is to use tree-ring records (Fritts, 2001). This approach is widely used in studying the effect of climate change on forest growth, and thus in forest management and ecological research. Studies in the tropics used treerings to understand forest dynamics, determine tree population structure, construct lifetime growth patterns, develop growth models, predict timber yield, and understand climate-growth relationships (e.g. Fichtler et al., 2003; Brienen and Zuidema, 2006;
Gebrekiristos et al., 2008; Couralet et al., 2010; Tolera et al., 2013). Emerging studies in the tropics also suggest that the dynamics of vegetation change and climate can better be understood across longer timeseries by integrating analyses of remote sensing, climate data, and tree-rings (Southworth et al., 2013; Mokuria et al., 2017). This can be used to establish linkages between locally created chronology and historical climate data, and also to link it to spatial and temporal features of remotely-sensed vegetation dynamics.

Despite its ability to quantify long-term variability in ecosystem productivity through the provision of an accurate and retrospective measure of tree growth, tree-ring study also has drawbacks. Its use involves intensive tasks starting from field works to collect wood samples up to the time-consuming laboratory works needed to crossdate and measure the samples. Besides, it is not applicable for non-ring forming tree species and has limited spatial domains (Bowman et al., 2013; Bunn et al., 2013). These drawbacks hinder its potential applicability for monitoring forest growth over large spatial scales. Thus, it is ideal to integrate tree-ring analysis and remotely-sensed vegetation 
indices to collect information on long-term growth dynamics and responses to changing climate conditions (Bunn et al., 2013; Southworth et al., 2013; Gebrekirstos et al., 2014; Qu et al., 2015). This is useful in developing restoration and sustainable management options in dryland vegetation (Mokuria et al., 2017).

The space-based vegetation indices, most importantly the Normalized Difference Vegetation Index (NDVI), have already been used as an ideal proxy for monitoring vegetation activity (Wang et al., 2004). It exhibits strong relationships with forest growth and can be used for estimating the Net Primary Production (NPP) (Wang et al., 2004; Bunn et al., 2013; VicenteSerrano et al., 2015; 2016). Therefore, studying the relations between NDVI and tree growth is vital for quantifying ecosystem primary productivity over large spatial and long temporal scales. Studies conducted mainly in the high latitude regions reported the existence of diverse relationships between NDVI and tree-growth metrics (e.g. ring width and maximum latewood density) across different regions and forest types (Wang et al., 2004; He and Shao, 2006; Bunn et al., 2013; Beck et al., 2011; 2013; Vicente-Serrano et al., 2016). However, little attempt has been made to explore the relationships and mechanisms between NDVI, tree-rings and climatic variables in the dry tropical regions (Shi et al., 2015). In the dry tropical regions, ecosystem production is highly determined by moisture availability unlike that of the high latitude regions. Therefore, similar associations are expected between NDVI and tree growth in the drier tropical bioregions. This study examined whether the spacebased vegetation productivity index (NDVI) correlates with the radial growth of the main tree species in the dry Afromontane forest remnants of northern Ethiopia.

\section{MATERIALS AND METHODS}

Study area: The study was conducted in Desa'a $\left(13^{\circ} 40^{\prime}\right.$ to $\left.13^{\circ} 50^{\prime} \mathrm{N}, 39^{\circ} 47^{\prime} \mathrm{E}\right)$ and Hugumburda $\left(12^{\circ} 38^{\prime} \mathrm{N}, 39^{\circ} 32^{\prime} \mathrm{E}\right.$ ) forests (Figure 1), the two major dry Afromontane forest remnants in northern Ethiopia. These forests are mainly located along the western escarpment of the Great Rift Valley facing the Afar depression (Aynekulu, 2011). The area falls in the semi-arid agro-ecological zone of Tigray region where the climate is influenced by topography and exposures to rain-bearing winds (Nyssen et al., 2005). The regional climate shows distinct seasonality in rainfall with a unimodal pattern. The mean annual rainfall was estimated at $532 \mathrm{~mm}$ in Desa'a (Abegaz 2005). and $981 \mathrm{~mm}$ in Hugumburda (Aynekule, 2011). The main rainy season occurs from June to September, while the remaining extended periods are more or less dry (Figure 2).

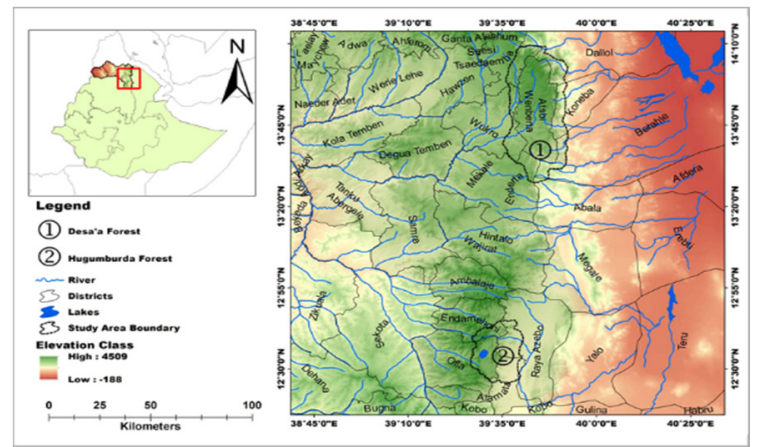

Fig 1: Location of the Study Area

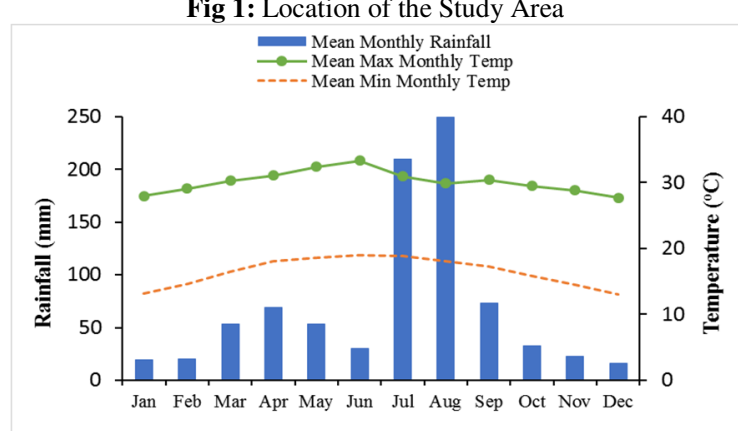

(a)

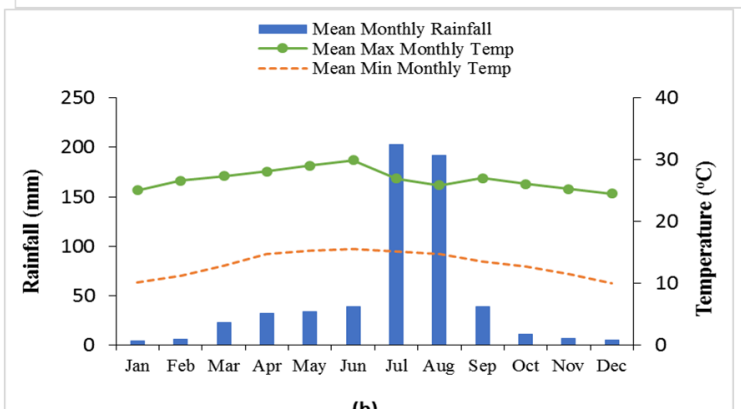

(b)

Fig 2: Mean Monthly Rainfall and Mean Monthly Temperature (Maximum and Minimum) Records (1980-2016) of the Study

Areas, (a) Hugumburda and (b) Desa'a, Northern Ethiopia.

Large areas of the forests are characterized by shallow soils and frequent rock outcrops. The dominant soil types are Leptosols, Cambisols, Vertisols, Regosols, and Arenosols (Aynekulu, 2011). The study sites are generally characterized by rugged topography. These forests are broadly classified as dry Afromontane forests and are dominated by Juniperus procera and Olea europaea subsp. cuspidata.

Tree-ring data: Tree-ring samples were collected from April to June 2017. Samples were taken from the dominant and co-occurring tree species of the dry Afromontane forest fragments in northern Ethiopia. Trees with no obvious injury or disease were carefully selected to minimize non-climatic influences (e.g. to minimize the effect of reaction wood and wounds on the ring-width patterns) on ring growth. Increment cores and/or stem discs were collected from a total of 106 trees belonging to three species, Juniperus 
procera, Olea europaea, and Podocarpus falcatus. For O. europaea subsp. cuspidata, only stem discs were collected due to its dense wood. In general, the number of stem discs was kept to a minimum to limit damage to the already threatened population of the tree species. For each tree, a cross-sectional wood disc was taken with a chainsaw and two increment core samples were collected per tree from opposite directions at breast height (about $1.3 \mathrm{~m}$ from the base of all trees) using an increment borer. The collected samples were carefully transported to, and open air-dried at the wood-science laboratory of Wondo Genet College of Forestry and Natural Resource, Ethiopia. After air-drying, the cores and stem discs were sanded and polished using progressively finer sanding papers (with a grit size of 60 to 600) to improve the visibility of the growth-ring boundaries and anatomical features (Schongart et al., 2006). Then, growth rings were first identified on stem discs following concentric features around the circumference. When all rings on a disc were detected, and ring numbers and characteristics matched along different radii, ring width was measured along 3-4 radii of each stem disc. Similarly, for increment cores, rings were marked, visually compared between the two cores and then measured. All ring-widths were measured to the nearest $0.001 \mathrm{~mm}$ using LEICA MS 5 microscope coupled with LINTABTM5 digital measuring stage associated to TSAP-dos software (Rinn, 2003). Ring measurements were performed along the predetermined radii in a straight line, and perpendicular to ring boundaries. The resulting growth-ring series were crossdated using standard dendrochronological protocols to ensure an accurate dating for each tree-ring (Cook et al., 1990). After all ring-width series were successfully crossdated, the quality of the crossdating was checked using a running correlation calculated under the program COFECHA (Holmes, 1983). A smoothing cubic spline (with 50\% wavelength cut-off), in time-windows of 32 years, was fitted to the ring-series of each individual tree of all species (Grissino-Mayer, 2001). This procedure was employed to remove the long-term growth trends from the raw measurements and filter out low-frequency variation attributed to disturbances other than the common signal of interest. After fitting a cubic spline curve, residuals were calculated by dividing each raw value by the predicted value of the fitted spline. The residual tree-ring series were compared by calculating Pearson correlations in different segment lengths, ranging between 30 and 35 years. By doing so, it was possible to detect apparent dating and measurement errors that may occur due to missing or wedging rings, which caused a shift in the tree ring series (i.e., higher correlations of series' segments at positions other than dated). Tree-ring series that showed low correlations than the critical threshold (at 99\% confidence level) provided by COFECHA were re-examined, considering recommendations on potentially missing or double rings provided by the program. Samples that failed to get fixed through this procedure were excluded from the analysis as the aim was to maximize the common signal of the series used for building the site chronology. Descriptive statistics were used to summarize the main characteristics of the site chronology. Annual radial growth rates were calculated by averaging ring widths from those individual measurements in the different radii. Then, species-specific tree level chronologies were established for each study site. For this purpose, individual growth-ring series were detrended and standardized using the dendrochronology program library in R programming language (dplR) (Bunn, $2008 ; 2010)$ to remove possible ontogenetic trends and low-frequency variation. The raw tree-ring series were standardized by fitting a cubic spline with the same stiffness as for the quality check (i.e., wavelength of 32 years with $50 \%$ cut-off). Detrending was used to estimate and remove the tree's natural biological growth trend. Standardization was done by dividing the original data by an estimated growth trend (estimated by the spline curve) to produce a dimensionless growth series (a stationary index series) free of autocorrelation caused by internal biological growth trends. Then, the standardized series were averaged to produce a single chronology per species in each study site. The final mean chronology of each species is a dimensionless ring-width index (RWI) (with mean equal to 1 and homogeneous variance).

Spatial data: The NDVI, a normalized ratio of the near-infrared and red spectral reflections, has wide applications in studies related to vegetation dynamics. Analysis of NDVI data helps in understanding the temporal trend of vegetation's biophysical features at different spatial scales. The Moderate Resolution Imaging Spectroradiometer (MODIS) NDVI datasets are widely used in vegetation trend analysis at different regional and local scales. The MODIS can provide moderate spatial and high temporal resolution data. The NDVI information from MODIS $250 \mathrm{~m}$ product has already been applied widely and has shown a significant relationship with vegetation properties (Piao et al., 2006; Hao et al., 2012), and it is an efficient indicator for vegetation photosynthesis dynamics (Seaquist et al., 2003). Thus, this study used NDVI data derived from MODIS13Q1 product from NASA (USGS) for the period 2000-2016, with a spatial resolution of $250 \mathrm{~m}$ and a temporal resolution of 16 days composites as a proxy for vegetation growth and change detection. The study considered homogenous forest patches where ring samples 
(nearest pixel values) were taken into account for the analysis (Mokuria et al., 2017).

The NDVI data acquired from the MODIS 16-days composite datasets were calculated by the amount of reflectance in near-infrared $\left(\rho_{2}\right.$ : Band $\left.2,858 \mathrm{~nm}\right)$ and red $\left(\rho_{1}\right.$ : Band 1, $\left.645 \mathrm{~nm}\right)$ portions of the electromagnetic spectrum. These have a spatial resolution of IFOV $250 \mathrm{~m}$.

$N D V I_{\text {MODIS }}=\left(\rho_{2}-\rho_{1}\right) /\left(\rho_{2}+\rho_{1}\right)$

Then, NDVI values were corrected by a scale factor (0.0001). The NDVI time-series were aggregated to monthly, seasonal and annual averages to detect the NDVI trends in the given time period. These values measure the seasonal and temporal pattern of vegetation greenness, vigor, or productivity. The dynamics in NDVI is used to assess the intra- and inter-annual dynamics in vegetation growth (Erasmi et al., 2014; Qu et al., 2015). Thus, annual and season NDVIs were generated by computing averages of the respective monthly NDVI values. Studies elsewhere (e.g. Bunn et al., 2013; Coulthard et al., 2017) showed the existence of relations between vegetation NDVI and radial growth (tree-ring width) of trees, and the possibilities of retrieving past NDVI using tree-ring data, and thereby examine vegetation growth dynamics over time. Thus, it is ideal to integrate these two approaches to reveal vegetation dynamics. In this study, the mean NDVI values were calculated in ArcGIS 10.3 using zonal statistics.

Data analysis: Pearson's correlation test was used to compare each tree-ring chronology with the nearest grid point of NDVI values and climate variables in each study site. The minimum, maximum and mean NDVI values were used to examine the correlation of NDVI values with standardized tree-ring widths (an index used to measure tree growth) in various time intervals. First, the tree-ring chronologies were compared with NDVI and climate records estimated on each study site. Then, the seasonal NDVI values were compared with climate data to determine whether the linkages between tree-rings and NDVI are driven by climate. Besides, a multiple linear correlation analysis was also used to derive the relationships between tree-growth and NDVI in the presence of climatic variables (rainfall and temperature). The NDVI values and climatic variables were used as independent variables to explain the vegetation growth. The monthly climate and NDVI data used in the analysis were standardized, and all analyses in this study were performed using the maximum common periods in the datasets. The correlation NDVI and tree- ring width index was analyzed during 2000-2016. R programming language software (mainly in $\mathrm{R}$ commander) was used for all the statistical data analyses. Results are statistically significant at $\mathrm{p}<0.05$ unless stated otherwise.

\section{RESULTS AND DISCUSSION}

Characteristics of the tree-ring chronologies: Results of the tree-ring analysis showing the radial growth rates of the sampled species in each site are presented in Table 1. Tree-ring width (TRW) varied considerably between sites, years and among the species. Samples from Hugumburda site showed higher radial growth rates than those in Desa' a site. In Hugumburda site, mean tree-ring widths of $2.3 \pm 0.54$ (mean \pm SD), $2.0 \pm 0.36$, and $2.5 \pm 0.58 \mathrm{~mm}$ were recorded for J. procera, O. europaea, and P. falcatus, respectively. The mean ring widths of J. procera and O. europaea from Desa'a site were $1.8 \pm 0.57$ and $1.6 \pm 0.20 \mathrm{~mm}$, respectively. In agreement with this, previous studies also reported comparable annual radial growth rates for various tree species growing in tropical dry forests and woodlands. For instance, Gebrekirstos et al. (2008) reported annual radial growth rates ranging between 1.81 and $2.53 \mathrm{~mm}$ for three deciduous acacia species and a co-occurring evergreen Balanites aegyptiaca trees growing in the dryland area of the central Rift Valley of Ethiopia. Similar annual radial growth rates were also reported for various tree species from elsewhere; $2.5 \mathrm{~mm}$ for Boswellia neglecta from the woodlands in southern Ethiopia (Mokria et al., 2017), 1.5-2 $\mathrm{mm}$ for Pterocarpus angolensis from Miombo woodland of Zimbabwe (Stahle et al., 1999), and 1.05-1.88 mm for Brachystegia spiciformis from the Miombo woodland in south-central Africa (Trouet et al., 2010). The radial growth rates reported for J. procera from elsewhere also showed considerable variations, ranging between $1.5 \mathrm{~mm}$ and $4.0 \mathrm{~mm}$ (Sass-Klaassen et al., 2008; Wils et al., 2009). Other studies reported lower values of mean annual radial growth rates; for instance, Tolera et al. (2013) reported annual radial growth rate of 1.15 $\mathrm{mm}$ for Boswellia papyrifera from the north-western woodlands of Ethiopia. Such variations indicate the sensitivity of tree growth to differing growing conditions and species-specific traits (Gebrekirstos et al., 2006; Sass-Klaassen et al., 2008). The longest tree-chronology, spanning from 1888 to 2016, was observed for $O$. europaea from Desa'a site, followed by that of $J$. procera from the same site which covered from 1905 to 2016. In Hugumburda site, however, the chronologies were relatively short due to the difficulties encountered to access very old trees, particularly for $O$. europaea and $P$. falcatus trees. 
Table 1: Characteristics of the tree ring series of the study species in each site in the dry Afromontane forest remnants of northern Ethiopia. $\mathrm{N}$ : number of crossdated tree ring series, MDI: mean diameter increment (SD, standard deviations) for each sampled tree species

\begin{tabular}{lllllll}
\hline Site & Species & $\begin{array}{l}\text { Time span } \\
\text { (years) }\end{array}$ & $\begin{array}{l}\text { Diameter } \\
\text { range }(\mathbf{c m})\end{array}$ & $\begin{array}{l}\text { Average no of } \\
\text { ring counts }\end{array}$ & $\begin{array}{l}\text { MDI } \\
\text { [SD] }\end{array}$ & N \\
\hline \multirow{3}{*}{ Hugumburda } & Juniperus procera & $1949-2016$ & $12-42$ & 43 & $0.47(0.11)$ & 33 \\
& Olea europaea & $1969-2015$ & $10-19$ & 36 & $0.41(0.07)$ & 10 \\
\multirow{2}{*}{ Desa'a } & Podocarpus falcatus & $1963-2016$ & $11-39$ & 35 & $0.49(0.11)$ & 18 \\
& Juniperus procera & $1905-2016$ & $14-50$ & 54 & $0.38(0.11)$ & 32 \\
& Olea europaea & $1888-2016$ & $16-35$ & 76 & $0.32(0.04)$ & 13 \\
\hline
\end{tabular}

The tree-ring chronologies of all the sampled species showed high year-to-year variability and a common environmental signal as clearly indicated by the high values of mean sensitivity $(0.43-0.63)$, standard deviation $(0.59-0.66)$, series intercorrelation $(0.51-0.57)$, and low values of average autocorrelation $(0.04-0.20)$. These statistical attributes of the tree-ring chronologies, such as high inter-series correlations and high mean sensitivity values show that the established chronologies are sensitive to climate variability (He et al., 2013). The higher year-to-year variability, expressed as mean sensitivity and low values of autocorrelation, indicates strong responses to annually changing environmental conditions (Sass-Klaassen et al., 2008). This is indicative for the synchronous growth patterns among individual trees of a given species, and that the studied tree species respond to a common climate forcing. Besides, the EPS (Expressed Population Signal) value for the study species ranged between 0.87 (O. europaea) and 0.93 ( $\mathrm{J}$. procera), which is higher than the threshold value (EPS $>0.85$ ) as suggested by Wigley et al. (1984). This is indicative of the quality of crossdating among the tree-ring series, and thus there is a common environmental signal which drives tree growth in the region.

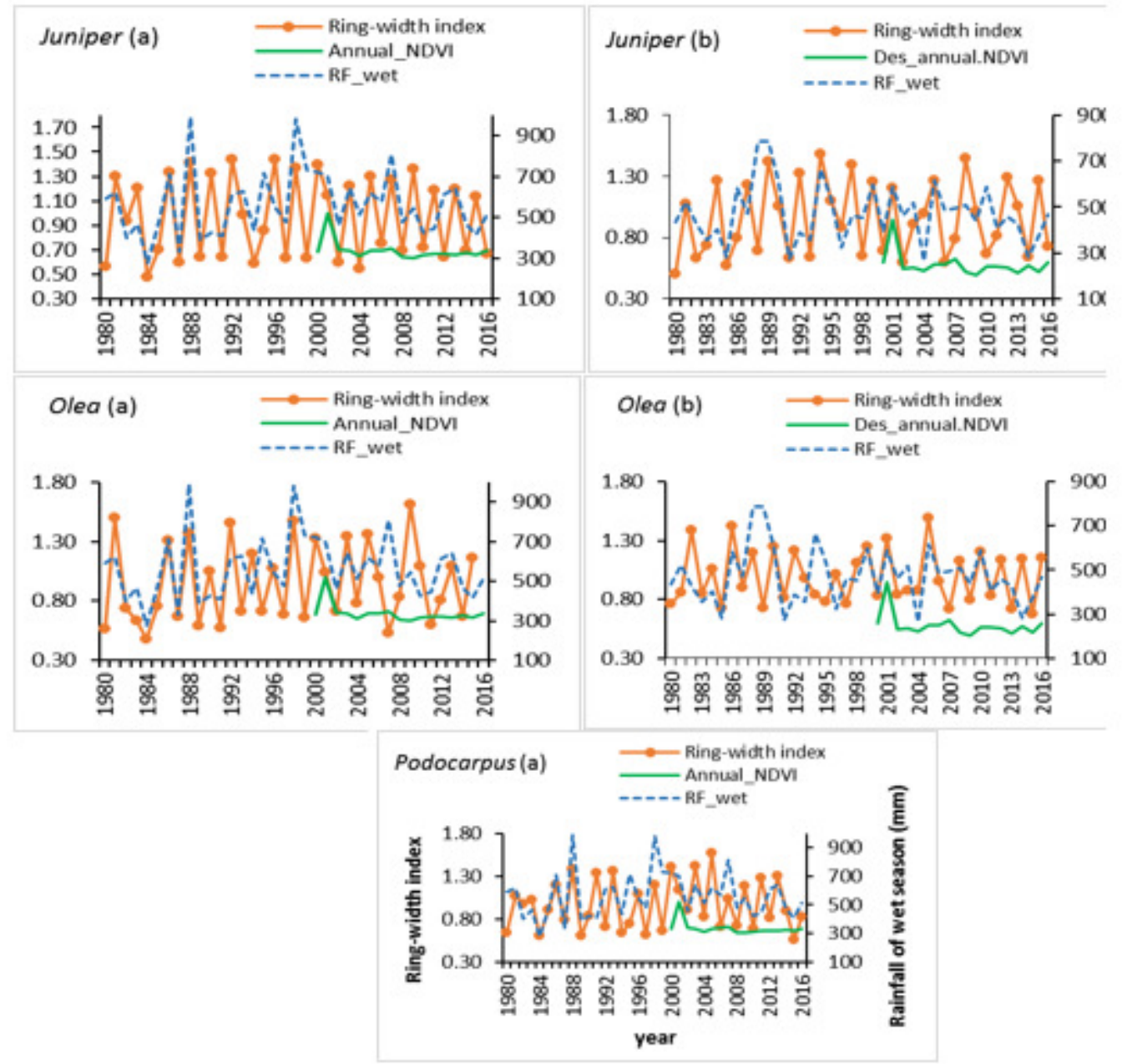

Fig 1: Comparison between rainfall during the wet season and ring-width series (1980-2016), and between ring-width and NDVI (2000 2016) from the two study sites, Hugumburda (a) and Desa'a (b), northern Ethiopia 
Table 2: Correlation coefficients (Pearson's r) between tree-ring indices and NDVI values for a dry Afromontane forest, northern Ethiopia

\begin{tabular}{lllll}
\hline Site & Species & Mean NDVI & Max NDVI & Min NDVI \\
\hline Hugumburda & Juniperus procera & 0.164 & 0.188 & 0.132 \\
& Olea europaea & 0.01 & 0.02 & -0.0003 \\
& Podocarpus falcatus & 0.174 & 0.262 & 0.112 \\
Desa'a & Juniperus procera & 0.10 & 0.13 & 0.01 \\
& Olea europaea & 0.44 & $0.54^{*}$ & 0.44 \\
\hline
\end{tabular}

Relations between tree growth and NDVI values: The NDVI has been used as an ideal proxy for monitoring vegetation activity (Wang et al., 2004). Various studies revealed that NDVI exhibits strong relationships with forest growth and can be used for estimating the Net Primary Production (NPP) (Wang et al., 2004; Bunn et al., 2013; Vicente-Serrano et al., 2015; 2016). Thus, it is generally expected to have a positive and statistically significant correlation between tree-growth and NDVI although diverse relationships may exist across different regions and forest types (Vicente-Serrano et al., 2016). Therefore, investigating the relations between NDVI and tree growth is vital for quantifying ecosystem primary productivity over large spatial and long temporal scales. Strong correlations between NDVI and tree growth were observed in both temperature-limited and drier bioregions in the high latitude sites, such as the boreal regions of Siberia and North America (e.g. Wang et al., 2004; Bunn et al., 2013). Thus, we expected similar relations in the dry tropics where ecosystem productivity is largely controlled by water availability. In this study, the relationship between forest growth and a remotely-sensed vegetation index (NDVI) was examined in the dry Afromontane forest remnants of northern Ethiopia for the periods 20002016. The study used tree-ring data of three species (i.e., J. procera, O. europaea and $P$. falcatus) from the study region and correlated it with the NDVI values. The tree-ring width and NDVI series and their relations during the common periods (2000-2016) are shown in Figure 3 and Table 2. The correlation between radial growth and NDVI was positive for the study species in each study site (Table 2). As expected, the maximum NDVI values in both study sites were recorded during the main rainy season and correspond with the tree-ring series. Results of this study concurs with various previous studies elsewhere. For instance, a study from the central Great Plains region of North America reported a strong relationship between Oak tree-ring width and NDVI (Wang et al., 2004). Vicente-Serrano et al. (2016) also found an overall positive relationship between the inter-annual NDVI variability and annual tree growth in most of the studied forests at global scale although the same study also witnessed strong differences in the relations between tree growth and NDVI values. In the same vein, studies from Siberia (Kirdyanov et al., 2007; Bunn et al., 2013), the arid and semi-arid regions in
China (He and Shao, 2006; Shi et al., 2015), the Cyprus, Eastern Mediterranean (Coulthard et al., 2017), and the semi-arid woodlands in southern Ethiopia (Mokuria et al., 2017) also found positive associations between NDVI and tree growth with varying strengths of correlations. These studies and results of this study support the claim that tree growth as measured by tree-rings and canopy reflectance (NDVI) are broadly related. This, in turn, implies that NDVI can serve as an ideal predictor of annual tree productivity. Hence, tree growth (tree-rings) and NDVI can be integrated to examine vegetation dynamics over larger spatial and longer temporal scales. Even though various studies reported positive and significant relationship between radial growth and NDVI in different regions, this claim may not be consistent at the global scale. Diverse relationships may exist between forest growth and NDVI at the global scale (Vicente-Serrano et al., 2016). Some studies in the high latitude regions, such as the temperature-limited boreal forests of North America, have found no significant relationship between NDVI and tree-ring width (Beck et al., 2011; 2013). On the other hand, Beck et al. (2013) found a good association between maximum latewood density and NDVI across vast regions of Northern America. These results support the claim which states the existence of strong differences regarding the relations between tree growth and NDVI across different climatic zones and vegetation types. Given that results of this study showed agreement between the inter-annual NDVI variability and the tree-ring series, it can be inferred that the tree-rings in the study region and the spacebased vegetation indices can be integrated to determine ecosystem primary productivity, and quantify terrestrial carbon budget. However, there is still a need to undertake similar studies at various spatial and temporal scales before making inferences about forest carbon stocks and fluxes.

Effect of climatic variables on tree growth and phenology: The study also analyzed the relationship between averaged NDVI values and the climatic variables (rainfall and temperature) for the common period spanning from 2000 to 2016. The correlation between rainfall and averaged NDVI values were positive in Hugumburda site, and it was positive and significant in Desa'a site $(r=0.51, \mathrm{p}<0.05)$. However, the correlations with maximum and minimum 
temperatures were negative and non-significant in both study sites. Results of the multiple correlation analysis (Table 3) depicted that an adequate amount of rainfall together with maximum temperature largely influences vegetation growth. Results of the climategrowth analyses also showed positive and significant relationships when the tree-ring chronologies were compared with annual rainfall and rainfall at the main growing season (i.e ., June - September, JJAS) (Table 4). Besides, relationships between tree growth and NDVI values were analyzed in the presence of specific climatic variable (temperature or rainfall) to identify the key driving factor. Table 5 shows results of the multiple linear correlation analysis. Relations that yielded the highest correlation coefficient (R) can be regarded as the most influential factors. Results of the multiple linear correlation analysis showed that rainfall contributes more than temperature in determining the dynamics of vegetation growth in the study region even though considerable variations were observed among the sampled species and between study sites. Overall, although the interactions between vegetation and climatic variables are more complex than expected, rainfall has a significant and positive influence on vegetation growth in the study region.

Table 3: Results of multiple linear correlation analysis $(\mathrm{R})$ showing the relationships between NDVI values and climatic variables in the dry Afromontane forest remnants of northern Ethiopia

\begin{tabular}{lllll}
\hline Site & Climatic variables & Annual NDVI & Maximum NDVI & Minimum NDVI \\
\hline \multirow{2}{*}{ Hugumburda } & Annual RF/ Tmax & 0.396 & 0.373 & 0.379 \\
& Annual RF/ Tmin & 0.331 & 0.390 & 0.330 \\
\multirow{2}{*}{ Desa'a } & Annual RF/ Tmax & 0.541 & 0.625 & 0.588 \\
& Annual RF/ Tmin & 0.315 & 0.647 & 0.641 \\
\hline
\end{tabular}

Table 4: Pearson correlation coefficients for the relations between the ring-width indices and total rainfall during distinct periods in a year with significant levels indicated (ns, non-significant; *, $0.01<\mathrm{p}<0.05 ; * *, 0.001<\mathrm{p}<0.01 ; * * *, \mathrm{p}<0.001)$.

\begin{tabular}{llll}
\hline \multirow{2}{*}{ Site } & \multirow{2}{*}{ Species } & \multicolumn{2}{l}{ Correlation (Pearson's) coefficients } \\
& Annual & Wet season (JJAS) \\
\hline \multirow{2}{*}{ Hugumburda } & Juniperus procera & $0.59^{* * *}$ & $0.56^{* * *}$ \\
& Olea europaea & $0.34^{*}$ & $0.43^{* *}$ \\
\multirow{2}{*}{ Desa'a } & Podocarpus falcatus & $0.52^{* * *}$ & $0.46^{* *}$ \\
& Juniperus procera & $0.22^{\mathrm{ns}}$ & $0.36^{*}$ \\
& Olea europaea & $0.35^{*}$ & $0.29^{\mathrm{ns}}$ \\
\hline
\end{tabular}

Table 5: Results of multiple linear correlation analysis (R) showing the relationships among NDVI values, climatic variables (rainfall and temperature) and tree-ring width of tree species from the dry Afromontane forest remnants of northern Ethiopia.

\begin{tabular}{|c|c|c|c|c|c|}
\hline Variables & $\begin{array}{l}\text { Desa'a site } \\
\text { Juniperus procera }\end{array}$ & Olea europaea & $\begin{array}{l}\text { Hugumburda site } \\
\text { Juniperus procera }\end{array}$ & Olea europaea & Podocarpus falcatus \\
\hline $\begin{array}{l}\text { Annual RF/ } \\
\text { Annual NDVI }\end{array}$ & 0.08 & 0.675 & 0.503 & 0.062 & 0.604 \\
\hline $\begin{array}{l}\text { Tmax/ } \\
\text { Annual NDVI }\end{array}$ & 0.297 & 0.521 & 0.165 & 0.264 & 0.236 \\
\hline $\begin{array}{l}\text { Tmin/ } \\
\text { Annual NDVI }\end{array}$ & 0.067 & 0.445 & 0.178 & 0.052 & 0.187 \\
\hline $\begin{array}{l}\text { Wet season RF/ } \\
\text { MaxNDVI }\end{array}$ & 0.198 & 0.617 & 0.545 & 0.149 & 0.548 \\
\hline
\end{tabular}

Unlike the high latitude regions where temperature is the primary factor determining vegetation growth, in the tropical regions, tree growth and hence overall vegetation dynamics is largely governed by moisture availability. Similarly, this study showed positive and significant (in most cases) relationship between rainfall and radial tree growth, as well as between rainfall and vegetation greenness. The coupling between NDVI and tree growth may be caused by the similar phenological processes of the main tree species and the entire dry Afromontane forest fragments in the study region. This interaction is particularly evident during the main growing season, suggesting that rainfall of the wet periods controls moisture availability and hence the cambial activity and phenological processes of the sampled tree species. This finding is in agreement with several other studies which reported that rainfall largely controls the cambial activities and phenology of various tree species growing in arid and semi-arid areas, including dry woodlands, savannas, and shrublands (He and Shao, 2006; Shi et al., 2015; Coulthard et al., 2017; Mokuria et al., 2017). This implies that moisture availability remains an overriding factor in determining the periodicity of cambial activities and phenological processes, and confirms that the amount and seasonality in rainfall largely control the changes in vegetation conditions in the study region.

Conclusion: The study found positive and moderate correspondence between tree growth and NDVI. The local moisture variations largely affected the growth patterns of the foundation tree species and hence the overall vegetation dynamics in the region. In sum, the 
study shows that tree-ring analysis and remotelysensed vegetation indices can be integrated to quantify landscape-level patterns of vegetation productivity. The study suggests the use of higher resolution remote sensing products and long-term tree ring records to better examine the relationships between tree growth and NDVI in different environmental and forest types across larger spatial and longer temporal scales.

Acknowledgment: The authors are grateful to the Pan African University (PAU), African Union (AU), Addis Ababa, Ethiopia for the financial support for this study. The authors would like to extend their gratefulness to all individuals who contributed for the successful accomplishment of this study. We also thank anonymous reviewers for their comments and suggestions.

\section{REFERENCES}

Abegaz, A (2005). Farm Management in Mixed CropLivestock Systems in the Northern Highlands of Ethiopia. PhD Thesis, Wageningen University, Netherlands.

Aynekulu, E (2011). Forest diversity in fragmented landscapes of northern Ethiopia and implications for conservation. PhD Thesis, Bonn University, Germany.

Beck, PS; Andreu-Hayles, L; D'Arrigo, R; Anchukaitis, KJ; Tucker, CJ; Pinzón, JE; Goetz, SJ (2013). A large-scale coherent signal of canopy status in maximum latewood density of tree rings at arctic treeline in North America. Glob. Planet. Change. 100: 109-118.

Beck, PS; Goetz, SJ (2011). Satellite observations of high northern latitude vegetation productivity changes between 1982 and 2008: ecological variability and regional differences. Environ. Res. Lett. 6(4), 045501.

Bowman, DM; Brienen, RJ; Gloor, E; Phillips, OL; Prior, LD (2013). Detecting trends in tree growth: not so simple. Trends plant sci. 18(1): 11-17.

Brienen, RJ; Zuidema, PA (2006). Lifetime growth patterns and ages of Bolivian rain forest trees obtained by tree ring analysis. J. Ecol. 94(2): 481493.
Bunn, AG (2008). A dendrochronology program library in R (dplR). Dendrochronologia. 26 (2): 115-124.

Bunn, AG (2010). Statistical and visual crossdating in $\mathrm{R}$ using the dplR library. Dendrochronologia. 28(4): 251-258.

Bunn, AG; Hughes, MK; Kirdyanov, AV; Losleben, M; Shishov, VV; Berner, LT; Oltchev, A; Vaganov, EA (2013). Comparing forest measurements from tree rings and a space-based index of vegetation activity in Siberia. Environ. Res. Lett. 8(3), 035034.

Cook, ER; Briffa, KR; Shiyatov, S; Mazepa, A; Jones, PD (1990). Data analysis. In: Cook ER, Kairiukstis LA (eds) Methods of dendrochronology: applications in the environmental sciences. Kluwer Academic Publishers, Dordrecht, p. 97-162.

Corlett, RT (2011). Impacts of warming on tropical lowland rainforests. Trends Ecol. Evol. 26(11): 606-613.

Coulthard, BL; Touchan, R; Anchukaitis, KJ; Meko, DM; Sivrikaya, F (2017). Tree growth and vegetation activity at the ecosystem-scale in the eastern Mediterranean. Environ. Res. Lett. 12(8), 084008 .

Couralet, C; Sterck, FJ; Sass-Klaassen, U; Van Acker, J; Beeckman, H (2010). Species-specific growth responses to climate variations in understory trees of a Central African rain forest. Biotropica. 42(4): 503-511.

Erasmi, S; Schucknecht, A; Barbosa, MP; Matschullat, J (2014). Vegetation greenness in northeastern Brazil and its relation to ENSO warm events. Remote Sens. 6(4): 3041-3058.

Fichtler, E; Clark, DA; Worbes, M (2003). Age and long-term growth of trees in an old-growth tropical rain forest, based on analyses of tree rings and 14C1. Biotropica. 35(3): 306-317.

Fritts, HC (2001). Tree Rings and Climate. Blackburn Press 567 pp.

Gebrekirstos, A; Bräuning, A; Sass-Klassen, U; Mbow, C (2014). Opportunities and applications of dendrochronology in Africa. Curr. Opin. Environ. Sustain. 6: 48-53. 
Gebrekirstos, A; Bräuning, A; Van Noordwijk, M; Mitlöhner, R (2011). Keynote paper: understanding past, present and future climate changes from East to West Africa. Agric. Innov. Sustainable Develop. 3: 77-86.

Gebrekirstos, A; Mitlöhner, R; Teketay, D; Worbes, M (2008). Climate-growth relationships of the dominant tree species from semi-arid savanna woodland in Ethiopia. Trees. 22(5): 631.

Gebrekirstos, A; Teketay, D; Fetene, M; Mitlöhner, R (2006). Adaptation of five co-occurring tree and shrub species to water stress and its implication in restoration of degraded lands. For. Ecol. Manag. 229(1-3), 259-267.

Grissino-Mayer, HD (2001). Evaluating crossdating accuracy: a manual and tutorial for the computer program COFECHA. Tree-ring research.

Hao, F; Zhang, X; Ouyang, W; Skidmore, AK; Toxopeus, AG (2012). Vegetation NDVI linked to temperature and precipitation in the upper catchments of Yellow River. Environ. Model. Assess. 17(4): 389-398.

He, J; Shao, X (2006). Relationships between tree-ring width index and NDVI of grassland in Delingha. Chin. Sci. Bull. 51(9): 1106-1114.

He, M; Yang, B; Bräuning, A; Wang, J; Wang, Z (2013). Tree-ring derived millennial precipitation record for the south-central Tibetan Plateau and its possible driving mechanism. Holocene, 23(1), 3645.

Holmes, RL (1983). Computer-assisted quality control in tree-ring dating and measurement. Tree-ring bull. 43(1): 69-78.

IPCC (2013). Fourth Assessment Report: Climate Change 2013 (AR5). Intergovernmental Panel on Climate Change.

Kirdyanov, AV; Vaganov, EA; Hughes, MK (2007). Separating the climatic signal from tree-ring width and maximum latewood density records. Trees. 21(1): 37-44.

Miles, L; Newton, AC; DeFries, RS; Ravilious, C; May, I; Blyth, S; Kapos v and Gordon, JE (2006). A global o verview of the conservation status of tropical dry forests. J. Biogeogr. 33(3): 491-505.

Mokria, M; Tolera, M; Sterck, FJ; Gebrekirstos, A; Bongers, F; Decuyper, M; Sass-Klaassen, U (2017). The franki incense tree Boswellia neglecta reveals high potential for restoration of woodlands in the Horn of Africa. For. Ecol. Manag. 385: 1624.

Nyssen, J; Vandenreyken, H; Poesen, J; Moeyersons, J; Deckers, J; Haile, M; Salles, C; Govers, G (2005). Rainfall erosivity and variability in the Northern Ethiopian Highlands. J. Hydrol. 311(1): 172-187.

Piao, S; Fang, J; He, J (2006). Variations in vegetation net primary production in the Qinghai-Xizang Plateau, China, from 1982 to 1999. Clim. Change. 74(1-3): 253-267.

Qu, B; Zhu, W; Jia, S; Lv, A (2015). Spatiotemporal changes in vegetation activity and its driving factors during the growing season in China from 1982 to 2011. Remote Sens. 7(10): 13729-13752.

Rinn, F (2003). TSAP-Win, Software for Tree-Ring Measurement. Analysis and Presentation. Rinntech, Heidelberg.

Sass-Klaassen, U; Couralet, C; Sahle, Y; Sterck, FJ (2008). Juniper from Ethiopia contains a largescale precipitation signal. Int. J. Plant Sci. 169(8): 1057-1065.

Schöngart, J; Orthmann, B; Hennenberg, KJ; Porembski, S; Worbes, M (2006). Climate-growth relationships of tropical tree species in West Africa and their potential for climate reconstruction. Glob. Change Biol. 12(7): 11391150 .

Seaquist, JW; Olsson, L; Ardö, J (2003). A remote sensing-based primary production model for grassland biomes. Ecol. Model. 169(1): 131-155.

Shi, Z; Xu, L; Dong, L; Gao, J; Yang, X; Lü, S; Feng, C; Shang, J; Song, A; Guo, H; Zhang, X (2015). Growth-climate response and drought reconstruction from tree-ring of Mongolian pine in Hulunbuir, Northeast China. J. Plant Ecol. 9(1): 51-60.

Southworth, J; Rigg, L; Gibbes, C; Waylen, P; Zhu, L; McCarragher, S; Cassidy, L (2013). Integrating dendrochronology, climate and satellite remote sensing to better understand savanna landscape dynamics in the Okavango Delta, Botswana. Land. 2(4): 637-655.

Stahle, DW; Mushove, PT; Cleaveland, MK; Roig, F; Haynes, GA (1999). Management implications of 
annual growth rings in Pterocarpus angolensis from Zimbabwe. For. Ecol. Manag. 124(2-3): 217229.

Tolera, M; Sass-Klaassen, U; Eshete, A; Bongers, F; Sterck, FJ (2013). Frankincense tree recruitment failed over the past half century. For. Ecol. Manag. 304: 65-72.

Trouet, V; Esper, J; Beeckman, H (2010). Climate/growth relationships of Brachystegia spiciformis from the miombo woodland in south central Africa. Dendrochronologia, 28(3), 161171.

Vicente-Serrano, SM; Camarero, JJ; Olano, JM; MartínHernández, N; Pea-Gallardo, M; TomásBurguera, M; Gazol, A; Azorin-Molina, C; Bhuyan, U; Kenawy, AE (2016). Diverse relationships between forest growth and the Normalized Difference Vegetation Index at a global scale. Remote Sens. Environ. 187: 14-29.
Vicente-Serrano, SM; Camarero, JJ; Zabalza, J; Sangüesa-Barreda, G; López-Moreno, JI; Tague, CL (2015). Evapotranspiration deficit controls net primary production and growth of silver fir: Implications for Circum-Mediterranean forests under forecasted warmer and drier conditions. Agric. For. Meteorol. 206: 45-54.

Wang, J; Rich, PM; Price, KP; Kettle, WD (2004). Relations between NDVI and tree productivity in the central Great Plains. Int. J. Remote Sens. 25(16): 3127-3138.

Wigley, TM; Briffa, KR; Jones, PD (1984). On the average value of correlated time series, with applications in dendroclimatology and hydrometeorology. J. Climate Appl. Meteorol. 23(2): 201-213.

Wils, TH; Robertson, I; Eshetu, Z; Sass-Klaassen, UG; Koprowski, M (2009). Periodicity of growth rings in Juniperus procera from Ethiopia inferred from crossdating and radiocarbon dating. Dendrochronologia, 27(1), 45-58 